\title{
Genotypic and phenotypic analysis of diarrheagenic Escherichia coli strains isolated from Brazilian children living in low socioeconomic level communities
}

\author{
Diego M Lozer', Tamara B Souza², Mariane V Monfardini', Fernando Vicentini ${ }^{3}$, Sônia S Kitagawa', \\ Isabel C A Scaletsky ${ }^{2 *}$ and Liliana C Spano ${ }^{1}$
}

\begin{abstract}
Background: Childhood diarrheal diseases remain highly endemic in developing areas of Brazil. The importance of Escherichia coli among children with diarrhea in these areas was unknown. This study determined the prevalence of different E. coli categories in symptomatic and asymptomatic children from low socioeconomic level rural communities in southeastern Brazil.

Methods: A total of 560 stool samples were collected from 141 children with diarrhea ( $<10$ years) and 419 apparently healthy controls who resided in 23 communities. E. coli isolates $(n=1943)$ were subjected to two multiplex PCRs developed for the detection of enteropathogenic E. coli (EPEC), enteroaggregative E. coli (EAEC), diffusely adherent E. coli (DAEC), enterotoxigenic E. coli (ETEC), enteroinvasive E. coli (EIEC), and Shiga toxin-producing E. coli (STEC). Strains were also examined for the presence of EPEC, EAEC, and DAEC by assays of adhesion to HEp-2 cells and by hybridization with specific DNA probes.
\end{abstract}

Results: Diarrheagenic E. coli strains were isolated from 253 (45.2\%) children, and were associated with diarrhea in children aged $<5$ years $(p<0.001)$. EAEC $(20.9 \%)$, DAEC $(11.6 \%)$, EPEC $(9.3 \%)$ were the most frequent pathotypes, followed by ETEC (2.7\%), EIEC (0.5\%), and STEC (0.2\%). Depending of the assay, EPEC, EAEC, and DAEC (collectively termed enteroadherent $E$. coli) strains were isolated in $45 \%$ to $56 \%$ of diarrhea cases, a significantly higher incidence than in controls $(P<0.05)$. Individually, only DAEC showed significant association with diarrhea $(p<0.05)$,

particularly in children aged $2-5$ years.

Conclusion: This study indicates that enteroadherent $E$. coli is an important cause of diarrhea in children living in low socioeconomic level communities in southeastern Brazil. Our results reveal that the PCR1 assay is an excellent tool for the identification of EAEC and DAEC.

\section{Background}

Diarrheal disease remains a major public health problem in developing countries, and is responsible for high morbidity and mortality among children under 5 years $[1,2]$. In Latin America, diarrheal diseases are responsible for $\sim 10 \%$ of childhood deaths [3]. Escherichia coli strains are among the most important bacterial causes of childhood diarrhea.

\footnotetext{
* Correspondence: scaletskyunifesp@gmail.com

${ }^{2}$ Departamento de Microbiologia, Imunologia e Parasitologia, Universidade Federal de São Paulo, Rua Botucatu, 862, 3 andar, 04023-062, São Paulo, Brazil

Full list of author information is available at the end of the article
}

Diarrheagenic E. coli (DEC) strains can be divided into six main categories on the basis of distinct epidemiological and clinical features, and specific virulence determinants [4]: enteropathogenic E. coli (EPEC), enterotoxigenic E. coli (ETEC), enteroinvasive E. coli (EIEC), enterohemorrhagic E. coli (EHEC) or Shiga-toxin producing E. coli (STEC), enteroaggregative $E$. coli (EAEC), and diffusely adherent $E$. coli (DAEC). EPEC is classified into typical and atypical strains based on the presence of the EPEC adherence factor (EAF) plasmid [4]. Although DEC strains are of public health relevance, they are not routinely sought as enteric

\section{Biomed Central}

(c) 2013 Lozer et al.; licensee BioMed Central Ltd. This is an Open Access article distributed under the terms of the Creative Commons Attribution License (http://creativecommons.org/licenses/by/2.0), which permits unrestricted use, distribution, and reproduction in any medium, provided the original work is properly cited. 
pathogens in clinical laboratories worldwide; thus the epidemiology of DEC infections remains obscure in many parts of world, particularly in endemic areas. Some assays for the detection of DEC are available, such as biochemical reactions, serotyping, phenotypic assays based on virulence characteristics, and molecular methods [4]. Among these, PCR is a commonly used method that gives rapid, reliable results with a high sensitivity and a high specificity. In order to simply diagnosis, we set up a two-reaction multiplex PCR assay for the detection of EPEC, EAEC, DAEC, ETEC, EIEC, and STEC, but so far has not been used in field studies [5].

In recent studies conducted in different urban centers of Brazil, aEPEC strains were found to be dominant and associated with diarrhea [6-9]. These studies also identified EAEC and DAEC in children with diarrhea. We conducted a prospective active diarrhea surveillance study to determine the importance of EPEC, EAEC and DAEC in rural communities with low socioeconomic level in southeastern Brazil using phenotypic and genotypic diagnostic tests.

\section{Methods}

\section{Ethical clearance, study site and population}

The study was approved by the Ethical Committee of Research (reference number 129/06) in the Health Science of Center at the Universidade Federal do Espírito Santo, Brazil. A consent form was read and signed by the parents or guardians of each child. The study was conducted in "quilombola" communities with low socioeconomic status located $256 \mathrm{~km}$ north of the city of Espirito Santo, Brazil. The "quilombola" communities are composed of descendents of slaves who escaped from slave plantations that existed in Brazil before abolition in 1880. These communities are predominately agricultural, and the population lives in slum conditions, with no access to potable water or sewage facilities. The households were visited once a week by nurses and trained community health workers. At each visit, the mother was asked a standard series of questions on her child's stool frequency, consistency, and physical nature. If a child had diarrhea, his or her hydration status was assessed. Generally fluid and nutritional management was recommended. Diarrhea was defined as the occurrence of three or more loose, liquid, or watery stools in a 24-h period. For every recruited case of diarrhea, three control stool samples were collected from children living in the same community, and who had not had diarrhea in the preceding two weeks. The control was agematched within 2 months for children $<1$ year of age and six months for older children.

\section{Specimen collection and processing}

Stool samples were collected and placed in Cary-Blair transport medium, and transported in iced boxes within 4 $\mathrm{h}$ to the laboratory at the Universidade Federal do Espírito
Santo. Samples were inoculated onto the surface of MacConkey and Hektoen agars for the selection of E. coli, Shigella, and Salmonella isolates. After incubation for $24 \mathrm{~h}$ at $37^{\circ} \mathrm{C}$, four lactose-fermenting colonies with typical $E$. coli morphology, and two non-lactosefermenting colonies were subjected to biochemical tests for identification. In addition, samples were analyzed for the presence of Giardia lamblia, Entamoeba hystolytica, and Cryptosporidium, using standard methods [10]. All E. coli strains were maintained in nutrient agar slants at room temperature.

\section{Multiplex PCR assays}

All $E$. coli isolates were subjected to two multiplex PCRs, as previously described, with some modifications [5]. PCR1 assay contained a primer mix for the detection of the following virulence markers: E. coli attaching and effacing (eae) gene (for detection of typical and atypical EPEC), EAF plasmid (for detection of typical EPEC strains), and the antiaggregation protein transporter gene (aat; previously referred to as CVD432 or the AA probe) (for detection of EAEC strains). Primers specific for $a f a / d a a$ for the detection of DAEC strains were subsequently included into this multiplex PCR. PCR2 assay contained primers specific for elt and est (enterotoxins of ETEC), ipaH (invasion plasmid antigen $\mathrm{H}$ found in EIEC and Shigella), and stx 1 and stx2 (Shiga toxins 1, 2 and variants of STEC). PCR1 assay identified EAEC, DAEC, and tEPEC by the presence of eae and $b f p A$, and aEPEC by the presence of only eae. PCR2 assay identified ETEC, EIEC, and STEC.

Three to six bacterial colonies from each stool sample were pooled for template DNA preparation immediately prior to PCR testing, suspended in $300 \mu \mathrm{L}$ of sterile water, and boiled for $10 \mathrm{~min}$. A $5-\mu \mathrm{L}$ aliquot of this suspension was added to $50 \mu \mathrm{L}$ of the PCR mixture (50 mM KCl, $10 \mathrm{mM}$ Tris- $\mathrm{HCl}$ [pH 8.3], $1.5 \mathrm{mM} \mathrm{MgCl}_{2}$, $2 \mathrm{mM}$ of each deoxynucleoside triphosphate), $1.5 \mathrm{U}$ of AccuPrime Taq DNA polymerase, and $5 \mu \mathrm{M}$ of each set of primers except for the ipaH primers, which used $10 \mu \mathrm{M}$. The reactions were run in a thermal cycler (model system 2400; Perkin-Elmer Corporation, Norwalk, Conn.) with the following cycling conditions: $94^{\circ} \mathrm{C}$ for $5 \mathrm{~min}, 40$ cycles of denaturation at $95^{\circ} \mathrm{C}$ for $1 \mathrm{~min}$, annealing at $58^{\circ} \mathrm{C}$ (assay 1) or $50^{\circ} \mathrm{C}$ (assay 2) for $1 \mathrm{~min}$ and primer extension at $72^{\circ} \mathrm{C}$ for 2 min followed by a final extension at $72^{\circ} \mathrm{C}$ for $7 \mathrm{~min}$. PCR products $(10 \mu \mathrm{L})$ were visualized after electrophoresis in $2 \%$ agarose gels in Tris-borate-EDTA buffer and ethidium bromide staining. In all assays, a mixture of DNA from the prototype EPEC E2348/69, EAEC 042, DAEC C1845, ETEC H10407, EIEC EDL1284, and STEC EDL931 strains served as the positive control, while $E$. coli $\mathrm{K}-12 \mathrm{DH} 5 \alpha$ was the negative control [4]. 


\section{HEp-2 adherence assay}

E. coli isolates were subjected to HEp-2 adherence tests by the method originally described by Scaletsky et al. [11], with slight modifications. Briefly, monolayers of $10^{5}$ HEp-2 cells were grown in Dulbecco modified Eagle medium containing $10 \%$ fetal bovine in 24-well tissue culture plates (Falcon Becton Dickinson). Bacterial strains were grown statically in $2 \mathrm{ml}$ of brain heart infusion for 16-18 h. The monolayers were infected with $\sim 3$ X $10^{7}$ bacteria ( $20 \mu \mathrm{l}$ of bacterial cultures added to $1 \mathrm{ml}$ of DMEM) and incubated at $37^{\circ} \mathrm{C}$ for $3 \mathrm{~h}$. The infected monolayers were washed with sterile PBS, fixed with methanol, stained with Giemsa stain, and examined for localized adherence (LA), diffuse adherence (DA), and aggregative adherence (AA).

\section{DNA hybridization}

E. coli isolates were tested by colony hybridization with the following DNA probes: EPEC adherence factor EAF (1-kb BamHI-SalI fragment of pMAR2 [12], E. coli attaching and effacing gene encoding intimin (eae) (1-kb KpnI-SalI fragment of pCVD434 [13], CVD432 (the nucleotide sequence of the EcoRI-PstI fragment of pCVD432 of EAEC) [14], and daaC (associated with the biogenesis of DAEC F1845 adhesin) (390-bp PstI fragment of pSLM852 [15]. DNA probes were prepared from recombinant plasmids containing the DNA probe fragments as inserts. Plasmids were extracted by the method of Birnboim and Doly [16] and digested with appropriate restriction endonucleases, and the appropriate restriction fragments were purified by gel extraction. The DNA fragments were labeled by a random primer extension kit (Rediprime DNA labeling system; Amersham) with $\left[\alpha-{ }^{32} \mathrm{P}\right] \mathrm{dCTP}$. Colony blots were prepared with Whatman 541 filter papers which were then processed and hybridized under string conditions as described previously [17].

\section{Statistical analysis}

The statistical analyses were performed using the SPSS version 17.0 (SPSS Inc., Chicago, IL). A sample size of 100 cases and 300 controls was estimated to have $80 \%$ power to detect the symptoms associated with infection, assuming a prevalence of $15 \%$ in controls and a $5 \%$ significance level. Statistical differences were evaluated by chi-square or Fisher's exact tests. A p value $<0.05$ was considered statistically significant.

\section{Results}

Between August 2007 and September 2008, 560 stool samples were collected from 141 children with diarrhea and 419 healthy controls who resided in 23 communities. Among the population studied, 150 (26.8\%) children were aged less than 2 years; 216 (38.6\%) and 194 (34.6\%) were aged 2-5 years and 6-10 years, respectively. The overall sex distribution was 296 (52.8\%) male and 264 (47.1\%) female.

$E$. coli isolates $(\mathrm{n}=1,943)$ were categorized into different pathotypes based on the results of two multiplex PCRs (Table 1). Diarrheagenic E. coli strains were isolated from $253(45.2 \%)$ children, and were associated with diarrhea in children aged $<5$ years $(\mathrm{p}<0.001)$. EAEC $(20.9 \%)$, DAEC (11.6\%), aEPEC (8.7\%) were the most frequent pathotypes, followed by LT-ETEC (2.3\%), tEPEC (0.5\%), EIEC (0.5\%), LT/ST ETEC (0.4\%), and STEC (0.2\%). Other enteric pathogens isolated were Shigella (0.7\%), Salmonella (0.2\%), Giardia lamblia (4.1\%), and Entamoeba hystolytica (0.9\%). Mixed infections were presented in 22 (15.6\%) cases and 12 (2.9\%) controls $(P<0.05)$.

$E$. coli isolates were further characterized into EPEC, EAEC, and DAEC pathotypes by HEp-2 adherence pattern and DNA probes. The results were compared with the PCR1 assay (Table 2). Of 145 isolates which yielded the AA pattern, 117 were detected by PCR1, and 99 of these strains reacted with the CVD432 probe; 18 EAEC isolates gave a positive-PCR but probe negative result. Similarly, PCR1 detected 65 of 104 isolates that yielded the DA pattern, and 57 of these strains reacted with the daaC probe; only 8 isolates gave a positive-PCR but probe negative result.

The combined incidence of EPEC, EAEC, and DAEC (collectively termed enteroadherent E. coli) isolates from diarrhea cases and controls is shown in Table 3. Enteroadherent $E$. coli strains were significantly associated with diarrhea, whether detected by phenotypic HEp- 2 cell assay or by genotypic assays ( $p<0.05)$. Depending of the assay used, enteroadherent $E$. coli strains were isolated in $45 \%$ to $56 \%$ of cases, a significantly higher incidence that in controls $(\mathrm{p}<0.05)$. Individually, only DAEC strains, detected either by adherence pattern or by PCR1 or by DNA probe, were significantly associated with diarrhea $(\mathrm{p}<0.05)$, particularly in children aged $2-5$ years.

\section{Discussion}

Diarrheal disease remains an important public health problem for children in developing areas of Brazil. The importance of $E$. coli as a cause of diarrhea and its attributable fraction to the diarrhea prevalence in these areas was unknown. The present study was performed to determine the prevalence of different diarrheagenic Escherichia coli categories in symptomatic and asymptomatic children living in low socioeconomic rural communities in southeastern Brazil.

We employed a two-reaction multiplex PCR assay for the detection of the six E. coli pathotypes. The PCR 1 contained primers for amplification of eae, EAF, aat, and afa/daa genes for identification of EPEC, EAEC, and 
Table 1 Isolation of pathogens (DEC strains by multiplex PCR) from the stools of children with diarrhea (cases) and children without diarrhea (controls)

\begin{tabular}{|c|c|c|c|c|c|c|c|}
\hline \multirow[t]{2}{*}{ Pathogen } & \multicolumn{2}{|c|}{ Children aged $<2$ years } & \multicolumn{2}{|c|}{ Children aged $2-5$ years } & \multicolumn{2}{|c|}{ Children aged $6-10$ years } & \multirow[b]{2}{*}{$\begin{array}{l}\text { Total no. of children } \\
(n=560)\end{array}$} \\
\hline & $\begin{array}{l}\text { Cases } \\
(n=40)\end{array}$ & Controls & Cases & Controls & $\begin{array}{l}\text { Cases } \\
(n=48)\end{array}$ & Controls & \\
\hline \multicolumn{8}{|l|}{ Diarrheagenic E. coli } \\
\hline aEPEC & $7(17.5)$ & $13(11.9)$ & $5(9.4)$ & $13(7.9)$ & $4(8.3)$ & $7(4.8)$ & $49(8.7)$ \\
\hline tEPEC & $1(2.5)$ & 0 & 0 & 0 & $2(4.2)$ & 0 & $3(0.5)$ \\
\hline EAEC & $20(50)$ & $25(22.7)$ & $12(22.6)$ & $33(20.2)$ & $4(8.3)$ & $23(15.7)$ & $117(20.9)$ \\
\hline DAEC & $5(12.5)$ & $10(9.1)$ & $15(28.3)$ & $18(11.0)^{\mathrm{a}}$ & $6(12.5)$ & $11(7.5)$ & $65(11.6)$ \\
\hline LT-ETEC & $2(5.0)$ & $1(0.9)$ & $3(5.7)$ & $2(1.2)$ & $1(2.1)$ & $4(2.7)$ & $13(2.3)$ \\
\hline LT/ST-ETEC & 0 & 0 & $1(1.9)$ & 0 & $1(2.1)$ & 0 & $2(0.4)$ \\
\hline EIEC & 0 & 0 & $2(3.8)$ & 0 & 0 & $1(0.7)$ & $3(0.5)$ \\
\hline STEC & 0 & 0 & 0 & $1(0.6)$ & 0 & 0 & $1(0.2)$ \\
\hline All & $35(87.5)$ & $49(44.5)^{b}$ & $38(71.7)$ & $67(41.1)^{c}$ & $18(37.5)$ & $46(31.5)$ & $253(45.2)$ \\
\hline Shigella spp. & $1(2.5)$ & 0 & $2(1.4)$ & $1(0.6)$ & 0 & 0 & $4(0.7)$ \\
\hline Salmonella spp. & 0 & $1(0.9)$ & 0 & 0 & 0 & $1(0.7)$ & $1(0.2)$ \\
\hline Giardia lamblia & $6(15)$ & $5(4.5)$ & $3(5.7)$ & $8(4.9)$ & $1(2.1)$ & 0 & $23(4.1)$ \\
\hline Entamoeba histolytica & 0 & 0 & $1(1.9)$ & $3(1.8)$ & $1(2.1)$ & 0 & $5(0.9)$ \\
\hline
\end{tabular}

${ }^{a} p=0.0041 ;{ }^{b} p=0.0001 ; c p=0.0001$, for the comparison between diarrhea and control samples.

DAEC. The PCR 2 contained primers for amplification of LT, ST, Inv, and Stx genes for detection of ETEC, EIEC, and STEC. We were able to validate the PCR1 with HEp-2 cell adherence assays and specific DNA probes. The different combination of adherence patterns and PCR primers showed that the HEp-2 adherence assay remains the "gold standard" for detection of EAEC and DAEC. Compared with DNA hybridization, our results showed that PCR1 assay could be used instead of the DNA probes as a screening method for "typical" EAEC $\left(a a t^{+}\right)$and "typical" DAEC $\left(a f a / d a a^{+}\right)$strains in the clinical laboratory [17].

Our results show a high proportion of EPEC, EAEC, and DAEC (collectively termed enteroadherent $E$. coli) accounting for $92.4 \%$ of DEC. EAEC was the most prevalent pathotype in both diarrhea cases and controls, in contrast with several studies showing an association with diarrhea $[18,19]$. In recent studies conducted in different urban centers of Brazil, EAEC strains were found to be dominant and associated with diarrhea [6-9]. By using the CVD432 probe for the detection of EAEC

Table 2 Detection of enteroadherent $E$. coli (ECC) isolated from cases and controls by genotypic and phenotypic tests

\begin{tabular}{lcccc}
\hline Diagnostic test & \multicolumn{4}{c}{ N. (\%) of isolates } \\
\cline { 2 - 5 }$(\boldsymbol{n}=\mathbf{5 6 0})$ & EEC & EPEC & EAEC & DAEC \\
\hline PCR assay & $234(41.8)$ & $52(9.3)$ & $117(20.9)$ & $65(11.6)$ \\
DNA probe & $206(36.8)$ & $50(8.9)$ & $99(17.7)$ & $57(10.2)$ \\
HEp-2 adhesion & $252(45)$ & $3(0.5)$ & $145(25.9)$ & $104(18.6)$ \\
\hline
\end{tabular}

strains, we found a correlation of $70 \%$ sensitivity, which is accordance with the levels of sensitivity found in other studies [6-9]. By using the PCR1, we found a sensitivity and specificity similar to those of the CVD432 probe.

DAEC strains, detected either by adherence pattern or by genotypic assays, were the second most frequently isolated pathotype (11.6-18.6\%) and were significantly

Table 3 Prevalence of enteroadherent $E$. coli (ECC) isolated from cases and controls detected by genotypic and phenotypic diagnostic tests

\begin{tabular}{lllll}
\hline Pathotype & Diagnostic test & $\begin{array}{l}\text { Cases } \\
(\boldsymbol{n}=\mathbf{1 4 1})\end{array}$ & $\begin{array}{l}\text { Controls } \\
(\boldsymbol{n}=\mathbf{4 1 9}\end{array}$ & p value \\
\hline ECC & PCR & $79(56)$ & $155(36.9)$ & 0.0001 \\
& DNA probe & $64(45.4)$ & $142(33.9)$ & 0.0156 \\
& HEp-2 adhesion & $78(55.3)$ & $174(41.5)$ & 0.0046 \\
EAEC & PCR & $36(25.5)$ & $81(19.3)$ & 0.1210 \\
& DNA probe & $27(19.1)$ & $72(17.2)$ & 0.6107 \\
& HEp-2 adhesion & $40(28.4)$ & $105(25)$ & 0.4385 \\
DAEC & PCR & $26(18.4)$ & $39(9.3)$ & 0.0057 \\
& DNA probe & $21(14.9)$ & $36(8.6)$ & 0.0369 \\
& HEp-2 adhesion & $35(24.8)$ & $69(16.5)$ & 0.0336 \\
EPEC & PCR (eae) & $16(11.3)$ & $33(8.3)$ & 0.2280 \\
& PCR (bfpA) & $1(0.7)$ & $2(0.5)$ & 1.0000 \\
& eae probe & $15(10.6)$ & $32(7.6)$ & 0.2923 \\
& EAF probe & $1(10.6)$ & $2(0.5)$ & 1.0000 \\
& HEp-2 adhesion & $1(0.7)$ & $2(0.5)$ & 1.0000 \\
\hline
\end{tabular}


associated with diarrhea, especially in children aged $2-5$ years. Similarly, in a prospective cohort study in a low socioeconomic level peri-urban community in Santiago, Chile [20], DAEC was found in a large proportion of diarrhea cases. In Mayan children in Mexico [21] and aboriginal children in Australia [22], DAEC strains were also predominant and associated with diarrhea. Taken together, these findings suggest that DAEC may be an important enteric pathogen in children living in endemic areas. Our results also support the evidence from studies showing an association of DAEC with agedependent diarrhea [20,22].

In this study, aEPEC was more common than tEPEC, with is concordance with current data suggesting that aEPEC is more prevalent than tEPEC in both developed and developing countries [4,23]. In Brazil, aEPEC has been increasingly reported and was recently implicated as a cause of diarrhea in different urban centers of Brazil [6-9]. Although differences in the population studied may exist, the prevalence of aEPEC in this and other studies underscores the emergence of aEPEC strains in Brazil.

The prevalence of ETEC was low, in agreement with other studies performed in different parts of Brazil [6-9]. EIEC and STEC were infrequently isolated, suggesting a less important role in diarrhea in Brazilian children [6-9].

\section{Conclusion}

We conclude that enteroadherent E. coli strains are involved in a significant proportion of diarrhea cases among children from low socioeconomic level communities. Apart from DAEC whose pathogenic role in diarrhea is still controversial, EAEC was the predominant E. coli pathotype. This should be taken as an alert for public health policies since the EAEC pathotype may harbor other very threatening virulence factors such as Shiga toxins. In addition, this study demonstrates that PCR1 assay is an excellent tool for the identification of EAEC and DAEC.

\section{Competing interests}

The authors declare that they have no competing interests.

\section{Authors' contributions}

LCS and SSK designed the study. FV were responsible for collection of specimens and clinical information. Laboratory investigations and data analysis were performed by DML, TBS, and MMV. ICSA assisted in the development of the research proposal and preparation of manuscript. All authors read and approved the final manuscript.

\section{Acknowledgements}

This work was supported by Fundação de Amparo a Pesquisa do Estado de Espírito Santo (FAPES), Fundação de Amparo a Pesquisa do Estado de São Paulo (FAPESP), and Conselho Nacional de Desenvolvimento Científico e Tecnológico (CNPq).

\section{Author details}

'Departamento de Patologia, Universidade Federal do Espirito Santo, Espirito Santo, Brazils. ${ }^{2}$ Departamento de Microbiologia, Imunologia e Parasitologia, Universidade Federal de São Paulo, Rua Botucatu, 862, 3 andar, 04023-062,
São Paulo, Brazil. ${ }^{3}$ Departamento de Ciências da Saúde, Universidade Federal do Espírito Santo, Espírito Santo, Brazil.

Received: 8 March 2013 Accepted: 28 August 2013

Published: 8 September 2013

\section{References}

1. Guerrant RL, Hughes JM, Lima NL, Crane J: Diarrhea in developed and developing countries: magnitude, special settings, and etiologies. Rev Infect Dis 1990, 12(Suppl 1):S41-S50.

2. Parashar U, Umesh D, Bresee JS, Joseph S, Glass Rl, Roger I: The global problem burden of diarrhoeal disease in children. Bull World Health Organ 2003, 81(4):236.

3. Organizacion Panamericana de la Salud/Organization Mundial de la Salud. Boletín AIEP 1997, 27:135-144.

4. Nataro JP, Kaper JB: Diarrheagenic Escherichia coli. Clin Microbiol Rev 1998, 11(1):142-201.

5. Aranda KRS, Fagundes-Neto U, Scaletsky ICA: Evaluation of multiplex PCRs for diagnosis of infection with diarrheagenic Escherichia coli and Shigella spp. J Clin Microbiol 2004, 42:5849-5853.

6. Araújo JM, Tabarelli GF, Aranda KS, Fabbricotti SH, Mendes CMF, FagundesNeto U, Scaletsky ICA: Typical enteroaggregative and atypical enteropathogenic types of Escherichia coli are the most prevalent diarrhea-associated pathotypes among Brazilian children. J Clin Microbiol 2007, 45:3396-3399.

7. Franzolin MR, Alves RC, Keller R, Gomes TAT, Beutin L, Barreto ML, Milroy C, Strina A, Ribeiro H, Trabulsi LR: Prevalence of diarrheagenic Escherichia coli in children with diarrhea in Salvador, Bahia, Brazil. Mem Inst Oswaldo Cruz 2007, 100:359-363.

8. Spano LC, Sadovsky ADI, Segui PN, Saick KW, Kitagawa SMS, Pereira FEL, Fagundes-Neto U, Scaletsky ICA: Age-specific prevalence of diffusely adherent Escherichia coli in Brazilian children with acute diarrhea. J Med Microbiol 2008, 57:359-363.

9. Moreno AC, Fernandes Filho A, Gomes TAT, Ramos STS, Montemor LPG, Tavares VC, Santos Filho L, Irino K, Martinez MB: Etiology of childhood diarrhea in the northeast of Brazil: significant emergent diarrheal pathogens. Diag Microbiol Infect Dis 2010, 66:50-57.

10. Murray PR, Baron MA, Pfaller MA, Tenover FC, Yolken RH: Manual of Clinical Microbiology. Washington: ASM Press; 1999.

11. Scaletsky ICA, Silva MLM, Trabulsi LR: Distinctive patterns of adherence of enteropathogenic Escherichia coli to HeLa cells. Infect Immun 1984, 45:534-536.

12. Nataro JP, Baldini MM, Kaper JB, Black RE, Bravo N, Levine MM: Detection of an adherent factor of enteropathogenic Escherichia coli with a DNA probe. Pediatr Infect Dis J 1985, 152:560-565.

13. Jerse AE, Jun $Y$, Tall BD, Kaper JB: A genetic locus of enteropathogenic Escherichia coli necessary for the production of attaching and effacing lesions on tissue culture cells. Proc Natl Acad Sci USA 1990, 87:7839-7843.

14. Baudry B, Savarino SJ, Vial P, Kaper JB, Levine MM: A sensitive and specific DNA probe to identify enteroaggregative $E$. coli, a recently discovered diarrheal pathogen. J Infect Dis 1990, 161:1249-1251.

15. Bilge SS, Clausen CR, Lau W, Moseley SL: Molecular characterization of a fimbrial adhesin, F1845, mediating diffuse adherence of diarrheaassociated Escherichia coli to HEp-2 cells. J Bacteriol 1989, 171:4281-4289.

16. Birnboim HC, Doly J: A rapid extraction procedure for screening recombinant plasmid DNA. Nucleic Acids Res 1979, 7:1513-1523.

17. Scaletsky ICA, Fabbricotti SH, Aranda KR, Morais MM, Fagundes-Neto U: Comparison of DNA hybridization and PCR assays for detection of putative pathogenic enteroadherent Escherichia coli. I Clin Microbiol 2002, 40:1254-1258.

18. Nguyen TV, Le Van P, Huy L, Gia KN, Weintraub A: Detection and characterization of diarrheagenic Escherichia coli from young children in Hanoi, Vietnam. J Clin Microbiol 2005, 43:755-760.

19. Sarantuya J, Nishi J, Wakimoto N, Erdene N, Nataro JP, Sheikh J, Iwashita M, Manago K, Tokuda K, Yoshinaga M, et al: Typical enteroaggregative Escherichia coli is the most prevalent pathotype among E. coli strains causing diarrhea in Mongolian children. J Clin Microbiol 2004, 42:133-139.

20. Levine ML, Ferreccio C, Prado V, Cayazzo PA, Martinez J, Maggi L, Baldini MM, Martin W, Maneval D, Kay B, Guers LM, Lior H, Wasserman SS, Nataro JP: Epidemiological studies of Escherichia coli diarrheal infections in a 
low socioeconomic level peri-urban community in Santiago, Chile.

Am J Epidemiol 1993, 138(10):849-869.

21. Girón JA, Jones T, Millán-Velasco F, Castro-munoz E, Zarate L, Fry J, Frankel G, Mosely SL, Baudry B, Kaper JB, Schoolnik GK, Riley LW: Diffuse-adhering Escherichia coli (DAEC) as a putative cause of diarrhea in Mayan children in Mexico. J Infect Dis 1991, 163:507-513.

22. Gunzburg ST, Chang BJ, Elliot SJ, Burke V, Gracey M: Diffuse and enteroaggregative patterns of adherence of enteric Escherichia coli from aboriginal children from the Kimberley region of Western Australia. $J$ Infect Dis 1993, 167:755-758.

23. Ochoa TJ, Ecker L, Baletta F, Mispireta ML, Gil Al, Contreras C, Molina M, Amemiya I, Verastegui H, Hall ER, Cleary TG, Lanata CF: Age-related susceptibility to infection with diarrheagenic Escherichia coli among infants from periurban areas in Lima, Peru. Clin Infect Dis 2009, 49:1694-1702.

doi:10.1186/1471-2334-13-418

Cite this article as: Lozer et al:: Genotypic and phenotypic analysis of diarrheagenic Escherichia coli strains isolated from Brazilian children living in low socioeconomic level communities. BMC Infectious Diseases 2013 13:418.

\section{Submit your next manuscript to BioMed Central and take full advantage of:}

- Convenient online submission

- Thorough peer review

- No space constraints or color figure charges

- Immediate publication on acceptance

- Inclusion in PubMed, CAS, Scopus and Google Scholar

- Research which is freely available for redistribution 